\title{
PROPIEDAD INTELECTUAL, DOMINIO PÚBLICO Y EQUILIBRIO DE INTERESES
}

\author{
INTELLECTUAL PROPERTY, PUBLIC DOMAIN AND BALANCE OF \\ INTERESTS
}

\section{CHRISTIAN SCHMITZ VACCARO*}

\begin{abstract}
RESUMEN: Con el afán de combatir la piratería y de mejorar la capacidad de generar innovaciones, se vienen ya desde algún tiempo impulsando políticas hacia mayores niveles de protección y resguardo de los derechos de propiedad intelectual. Sin embargo, la importancia del dominio público parece haber caído en el olvido. Una extensión adecuada del dominio público reviste igual trascendencia como la adecuada protección de los derechos intelectuales, a la hora de asegurar incentivos para investigadores y creadores. Es por ello que se hace indispensable fijar un cuidadoso equilibro de la función individual y social de la propiedad intelectual, equilibrio que implica conciliar los intereses de titulares y usuarios.
\end{abstract}

Palabras clave: dominio público, derecho de autor, propiedad intelectual, equilibrio de intereses, desarrollo económico

ABSTRACT: In order to fight counterfeiting and to improve the capacity to generate innovation, policies for greater levels of protection and enforcement of intellectual property rights have strongly been pushed. However, the importance of public domain seems to have been forgotten. An appropriate extension of the public domain, is as important as the proper protection of intellectual property rights, to secure incentives to researchers and creators. That is why it is indispensable to establish a careful balance of individual and social role of intellectual property, between holders and users of IP rights.

Key words: Public domain, copyright, intellectual property, balance of interests, economic development

\section{INTRODUCCIÓN}

Con frecuencia observamos que determinadas personas o grupos reclaman mayores niveles de protección de los derechos de propiedad intelectual. Estos llamados se fundan generalmente en dos razonamientos distintos, ambos en principio independientes entre sí y atribuibles a cada uno de los dos subsistemas que constituyen la propiedad intelectual ${ }^{1}$.

\footnotetext{
* Licenciado en Ciencias Jurídicas de la Universidad de Concepción, Master en Administración de Empresas MBA UC. Profesor de Derecho Económico y informático Universidad de la Santísima Concepción, Jefe del Departamento de Derecho Económico y Laboral de la misma Universidad. Correo electrónico: schmitz@ucsc.cl

${ }^{1}$ Los dos subsistemas o vertientes de la propiedad intelectual son por un lado los derechos de autor, y por el otro los derechos de propiedad industrial.
} 
El primer razonamiento, bastante conocido y difundido, se basa en la "piratería", es decir, en la utilización no autorizada de obras protegidas por derechos de autor y de interpretaciones, producciones y emisiones protegidas por derechos conexos. Las obras objeto de dicho delito son principalmente las musicales, cinematográficas, literarias y el software. En este sentido, las empresas, especialmente discográficas, cinematográficas editoriales y distribuidores de software, han planteado la necesidad de elevar las sanciones y tutelas de los derechos autorales y conexos, así como de controlar y aplicarlas eficazmente como forma de combatir por la vía jurídica los delitos de "piratería" 2 .

La segunda cadena argumentativa para implementar mejoras en la protección de los derechos de propiedad intelectual es menos conocida y más bien de reciente data en nuestros países. Este razonamiento que proviene de la vertiente de la propiedad industrial, será expuesto a continuación con mayor detalle.

Existe una conciencia cada vez mayor de la importancia que tiene la innovación para alcanzar mayores niveles de desarrollo económico. Así, es frecuente escuchar los llamados de los gobiernos, pero también de otros sectores, que instan a mejorar el desempeño innovador de las economías nacionales. El fundamento para ello puede resumirse en las siguientes palabras: "... Chile se encuentra hoy en una encrucijada. En el corto plazo podrá seguir gozando de las rentas que producen los commodities ligados a los recursos naturales, pero luego, cuando tarde o temprano estas declinen, se desacelerará en forma significativa nuestro crecimiento económico y nuestra capacidad para generar empleo y aumentar el bienestar social. Este cuadro nos muestra, ... que si Chile no avanza, pronto y rápido, en innovación y transferencia tecnológica, nos vamos ir rezagando, a tal punto, que nuestras ventajas competitivas estáticas de hoy pueden verse seriamente amenazadas y desplazadas ..."

Constituyéndose la innovación en un tema recurrente, se observa por lo general consenso acerca de la necesidad de tomar medidas incentivadoras. Comúnmente se recomienda invertir mayores recursos en investigación y desarrollo, por tratarse del proceso que da origen a la innovación ${ }^{4}$. Igualmente se señala como condición esencial

\footnotetext{
${ }^{2}$ En relación a los altos niveles de piratería de obras protegidos por el derecho de autor, sea dicho que, generalmente las soluciones que a primera vista se proponen son de carácter jurídico, en razón a la ilegalidad de dichas prácticas. Sin embargo, existen una serie de medidas no jurídicas (fundamentalmente de índole económica), que son recomendadas por los expertos, y que buscan alterar la relación costobeneficio de las conductas piratas; tales como la rebaja de precios, ofertas y promociones, ventas combinadas (bundling), u otros incentivos que impliquen aumentar el valor al cliente.

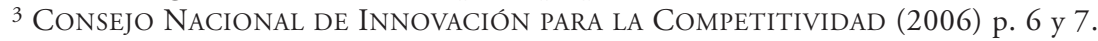

El mismo informe (pág. 9) aclara el significado de tan relevante término: Innovación designa "aquel proceso mediante el cual ciertos productos o procesos productivos, desarrollados en base a nuevos conocimientos o a la combinación novedosa de conocimiento preexistente, son introducidos eficazmente en los mercados, y por lo tanto en la vida social".

De la lectura de la definición puede deducirse que la innovación no es un proceso aislado, sino que forma parte de una cadena compleja integrada por varios procesos que se desarrollan en el tiempo. Las distintas etapas se desencadenan a partir del desarrollo de nuevos conocimientos o la combinación novedosa de conocimiento preexistente, lo cual puede suceder en el marco de un proceso de investigación y desarrollo (I \& D).

4 En Chile, el año 2004, "solo" el 0,67\% del PIB se ha invertido en investigación y desarrollo. En comparación, los países de la OECD invierten en promedio un 2,26\% de su PIB para tales fines. Fuente: Organisation For ECONOMIC COOPERATION AND DEVElopment (2008) p. 166.
} 
para el mejoramiento del desempeño innovador de los países, la necesidad de contar con sistemas jurídicos que resguarden eficazmente los derechos de propiedad intelectual. En nuestro medio, ello a menudo se ha interpretado en el sentido de elevar el nivel de protección legal de dichos derechos.

Si bien en teoría, aspirar a una protección amplia de dichos derechos inmateriales resulta absolutamente razonable, dado que estaríamos fortaleciendo la creatividad y la cultura en el caso del derecho del autor, y en el caso de la propiedad industrial, la investigación y desarrollo ( $\&$ D), podemos observar que en este punto se desatan discusiones que son de las más relevantes en materia de propiedad intelectual. El fondo del debate radica en la búsqueda de un sistema de propiedad intelectual que proteja suficientemente los derechos individuales, pero sin descuidar los intereses de la sociedad, reconociendo la existencia del llamado "dominio público".

El presente trabajo tiene por objeto inicial dilucidar la importancia que tiene el dominio público para la humanidad, cómo se compone y su relación con la propiedad intelectual. Enseguida, contextualizaremos el rol del dominio público y de la propiedad intelectual en el conflicto de intereses, describiendo las posiciones ideológicas de dicha controversia y las posibles soluciones. En todo momento se tratará de mantener un enfoque integral de propiedad intelectual, que cubra tanto derecho de autor como la propiedad industrial.

\section{RELACIÓN ENTRE PROPIEDAD INTELECTUAL Y DOMINIO PÚBLICO}

Expresado en forma simple, podemos conceptualizar la propiedad intelectual "como un conjunto de derechos temporales, exclusivos y excluyentes destinados principalmente a impedir falsificaciones o copias no autorizadas de las creaciones-materiales o inmateriales-

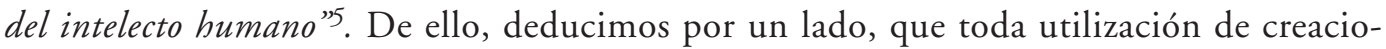
nes o producciones intelectuales requiere de la autorización de su creador o productor titular, y por el otro, que estos derechos constituyen un verdadero monopolio temporal en la explotación comercial de inventos u obras, concedido a una persona -natural o jurídica- quien será el creador intelectual o su cesionario.

Por su parte, la Organización Mundial del Comercio (OMC) entrega la siguiente definición: "Los derechos de propiedad intelectual son aquellos que se confieren a las personas sobre las creaciones de su mente. Suelen dar al creador derechos exclusivos sobre la utilización de su obra por un plazo determinado"'.

Esta exclusividad requiere ser resguardada legalmente, pues constituye el incentivo tanto para la investigación y desarrollo de nuevas tecnologías como para la creación de obras literarias, artísticas o científicas. Desde un punto de vista netamente económico, el inventor o creador puede considerarse un "inversionista" que asume riesgos, e invierte dinero, tiempo y trabajo en un proyecto cuyo resultado esperado es una creación novedosa u original. Pero antes de emprender el proyecto y decidirse a realizarlo, este "inver-

\footnotetext{
5 SCHMITZ (2005) p. 17.

${ }^{6}$ Organización Mundial del Comercio (2008).
} 
sionista” evaluará costos y beneficios, es decir la relación entre la inversión inicial y el retorno esperado. Evidentemente este enfoque económico no considera beneficios para la persona creadora derivados de la búsqueda de realización personal, del seguimiento de su vocación y del impulso creador innato, que confluyen a la hora de emprender tareas investigativas y, especialmente en la creación de obras literarias o artísticas.

Por su parte, el dominio público, también llamado frecuentemente "patrimonio común", lo podríamos definir como el estado jurídico consistente en el libre acceso y utilización de creaciones intelectuales, sean estas expresiones o innovaciones industriales u obras sujetas al derecho de autor, sin que nadie pueda hacer valer derechos intelectuales sobre las mismas. En consecuencia, implica la no existencia de la exclusividad inherente a los derechos de propiedad intelectual, sin que persona alguna pueda "apoderarse", apropiarse o volver a implantar exclusividad sobre la respectiva creación ${ }^{7}$. La determinación de este espacio de "información y conocimientos libres y liberalizados" si bien es entregado a la ley, se encuentra expuesta al debate político coyuntural, razón por la cual genera arduas discusiones ideológicas.

De acuerdo a lo visto al definir la propiedad intelectual, los diversos derechos que la integran se caracterizan especialmente por su temporalidad. Con ello pudiera llegar a sostenerse que el dominio público se configura simplemente por los derechos de propiedad intelectual cuyo plazo de vigencia haya expirado en el tiempo, y como las marcas no expiran en el tiempo mientras se renuevan, no habría dominio público a su respecto. Sin embargo, estimamos que existen otras importantes fuentes del dominio público: las exclusiones, limitaciones y excepciones de derechos intelectuales. En efecto, el sistema jurídico de la propiedad intelectual es demarcado por un lado, por ciertas exclusiones, excepciones o limitaciones, y por el otro, a través de plazos de protección de los derechos intelectuales; ambos influyen directamente en la extensión del campo del dominio público. En otras palabras, aquella "propiedad común” recae principalmente sobre las creaciones intangibles que no son susceptibles de ser protegidos a través de la propiedad intelectual o cuyos derechos intelectuales ya hayan expirado en el tiempo.

Esta distinción de las fuentes del dominio público nos permite establecer la siguiente clasificación de dominio público:

1) dominio público estable o permanente en el tiempo, que incluye aquellos conocimientos o creaciones no susceptibles de ser reivindicado a través de un derecho de propiedad intelectual por el hecho de que una ley los excluye de tal ámbito. Sería el caso de las exclusiones de derechos de propiedad industrial y limitaciones y excepciones del derecho de autor que por lo general son taxativamente enumerados por la ley.

\footnotetext{
7 Precisamente, la no apropiabiabilidad es la característica que diferencia un bien (en sentido amplio) integrado en el dominio público de un bien abandonado. En efecto, la "Res nullius" se basa en una presunción de que la cosa es de nadie, y por consiguiente cualquiera que la encuentre pudiera apropiarse de ella. En cambio, en la "Res communis" la cosa es de todos los hombres, de la humanidad, no admitiéndose apropiación individual.
} 
2) dominio público creciente en el tiempo, que se incrementa día a día precisamente por el vencimiento del plazo legal de protección de los derechos de propiedad intelectual. Está compuesto por creaciones intelectuales e industriales que se liberan del ámbito de protección de la propiedad intelectual. En el caso de los derechos de patente, este conocimiento liberado ya posee cierta antigüedad, por lo cual muchas veces resulta obsoleto y superado por conocimientos que han emergido con posterioridad; por lo mismo su valor científico puede ser reducido.

Con lo anterior queda claro que el dominio público ha sido concebido como un "espacio" residual, pudiendo describirse como la faz negativa de los derechos individuales de propiedad intelectual susceptibles de protección legal.

Evidentemente el dominio público beneficia a la comunidad como un todo, pero también juega un rol esencial en la generación de nuevas creaciones y producciones intelectuales, y por ende para investigadores, científicos, educadores, artistas, autores y creadores que requieren acceder al estado de la técnica y de la cultura. Para comprender esta relación, hay que explicar en forma previa, un supuesto común a prácticamente toda actividad creativa-inventiva: hoy en día, todo avance tecnológico, científico y cultural no es un hecho aislado, sino que debe mirarse dentro del contexto complejo propio de toda creación inserta en uno o más sectores del conocimiento de la humanidad. Así toda creación intelectual o industrial es generada aprovechando los esfuerzos colectivos desarrollados por muchas generaciones de creadores o investigadores anteriores. Pudiéramos decir que "no hay nada enteramente nuevo". Siguiendo el razonamiento, observamos que el acervo existente de conocimientos y creaciones humanas puede estar válidamente amparado por un registro de propiedad intelectual, o puede integrar el "patrimonio común de la humanidad" 8 . Esta distinción es importante para los nuevos creadores-inventores, puesto que en el primer caso tendrían que pagar a los titulares del derecho intelectual vigente por la utilización del conocimiento necesario para desarrollar y comercializar algo nuevo, mientras que en el segundo caso, la utilización de los conocimientos pertenecientes al dominio público es gratuita y de libre acceso. Pero el hecho de basar una nueva creación o invención en derechos intelectuales vigentes, no solo implica un encarecimiento del proceso creativo-inventivo, sino que además no existe garantía o certeza de poder a su vez proteger el resultado dentro del sistema de propiedad intelectual, ni de poder difundirlo con posterioridad. De más está señalar que calificar en estas circunstancias, el carácter novedoso u original de una invención u obra es una tarea que tiene un alto grado de relatividad (que varía de país a país en el caso de la propiedad industrial), puesto que generalmente resulta muy difícil determinar hasta

\footnotetext{
${ }^{8}$ No utilizamos el término "patrimonio común de la humanidad" en un sentido meramente cultural, sino que más bien amplio, para referirnos a todo tipo de creaciones y producciones intelectuales generadas por el hombre y que no se encuentran sujetas a restricción de uso debido a la existencia de derechos intelectuales vigentes. De esta forma abarca tanto las obras creativas como las producciones industriales.

Por lo mismo, no hay que confundir este concepto, con el término más restringido del "patrimonio cultural común" que utiliza nuestra ley de propiedad intelectual $\left(\mathrm{n}^{\circ} 17.336\right)$ en su artículo 11.
} 
qué punto una obra o invención, que incorpora legítimamente elementos de otras creaciones intelectuales ya registradas, mantiene ese carácter.

En suma, considerar la relevancia del dominio público tiene amplias consecuencias en el desarrollo continuo de la tecnología, de las ciencias y de las artes, puesto que dicho espacio público no solo se constituye para un goce pasivo del público, sino que servirá directamente al interés privado de quienes activamente deseen seguir investigando, desarrollando o creando innovaciones $\mathrm{u}$ otro tipo de expresiones intelectuales. El dominio público, al igual como la propiedad intelectual, asegura la difusión del estado del arte y de la técnica. En efecto, son ciertos intermediarios, tales como las bibliotecas, museos, archivos, establecimientos educacionales e instituciones académicos, los que cumplen un rol de diseminación de los contenidos al alcance de todos los integrantes de la sociedad.

Esta función del dominio público en el avance de las ciencias y de la cultura, ha sido reconocida por numerosos declaraciones y recomendaciones internacionales?.

Si bien el dominio público puede considerarse un concepto universal que beneficia a todos los hombres sin considerar nacionalidades, hay que precisar que la efectiva delimitación del campo de la propiedad intelectual queda entregada a las legislaciones nacionales. Es de esta forma como queda definido para cada país un espacio residual más o menos amplio, que corresponde al dominio público del respectivo país y que es aprovechable por nacionales y extranjeros por igual. Al respecto, solo basta pensar en las normas sobre impatentabilidades o plazos de protección de los derechos intelectuales

9 En el marco de la Agenda de Desarrollo de la Organización Mundial de Propiedad Intelectual, el Gobierno chileno presentó con fecha 9 de enero de 2006, un documento al "Comité Provisional sobre Propuestas relativas a un Programa de la OMPI para el Desarrollo" (PCDA) que enumera las "distintas declaraciones y recomendaciones" del ámbito de las Naciones Unidas que reconocen el dominio público: - Resolución 29 C/28 de la Conferencia General de la Organización de las Naciones Unidas para la Educación, la Ciencia y la Cultura (UNESCO) en 1997, que llama a hacer lo necesario para "facilitar el acceso a la información de dominio público con el fin de constituir, a largo plazo, un repertorio electrónico general de toda la información de carácter público relacionada con las esferas de competencia de la UNESCO". - Declaración Universal de la UNESCO sobre la Diversidad Cultural, adoptada por la $31^{\text {a }}$ Reunión de la Conferencia General de la UNESCO, el 2 de noviembre de 2001, que en sus orientaciones establece que los Estados se comprometen con el objetivo de "fomentar el acceso gratuito y universal, a través de las redes mundiales, a todas las informaciones que pertenecen al dominio público".

- "Recomendación sobre la promoción y el uso del plurilingüismo y el acceso universal al ciberespacio", aprobada por la Conferencia General de la UNESCO en noviembre de 2003.

- Declaración de Principios de la Primera Cumbre Mundial de la Sociedad de la Información, cuyo artículo 26 señala: "Un dominio público rico es un factor capital del crecimiento de la sociedad de la información, ya que genera ventajas tales como un público informado, nuevos empleos, innovación, oportunidades comerciales y el avance de las ciencias. El acceso sin dificultad a la información del dominio público es esencial en la sociedad de la información, como lo es la protección de dicha información contra toda apropiación indebida [...]", y;

- Plan de Acción de la Cumbre Mundial sobre la Sociedad de la Información (CMSI) de 2003, que mediante un documento de fecha 12 de mayo de 2004, señala en su párrafo 10 a, la necesidad de "definir directrices políticas para el desarrollo y promoción de la información en el dominio público, como un importante instrumento internacional que promueve el acceso de todos a la información".

Fuente: GobIERNO DE CHILE (2006) p. 3 y 4. 
que generalmente varían de un Estado a otro. Naturalmente existen ciertos componentes básicos que son considerados dominio público en todos los países del mundo, y en esos casos podemos realmente hablar de "patrimonio común de la humanidad"10. Ejemplo típico para ello son las obras clásicas sean de la literatura universal, de música clásica, etc., pero también conocimientos tecnológicos históricos, como son los inventos correspondientes a la época de la Revolución Industrial.

\section{CONFIGURACIÓN DEL DOMINIO PÚBLICO}

Anteriormente ya hemos propuesto una primera clasificación de dominio público. A continuación, precisaremos cómo se configura el dominio público de cada uno de los principales derechos intelectuales, utilizando una segunda clasificación en base a los distintos derechos de propiedad intelectual. Así, distinguiremos:

1. dominio público de las marcas

2. dominio público de las patentes, y

3. dominio público de los derechos de autor.

Cabe hacer presente que ambas clasificaciones de dominio público no son excluyentes entre sí.

\subsection{EL DOMINIO PÚBLICO EN EL ÁMBITO DE LAS MARCAS}

En lo relativo a las marcas comerciales, el dominio público estaría constituido por los signos de uso común, habitual o general, incluyendo expresiones genéricas y descriptivas. Su uso estará reservado a todas las personas, sin que se pueda establecer exclusividad al respecto.

Las legislaciones traducen esta consideración de dominio público mediante la consagración de determinadas causales de irregistrabilidad. Muchos ordenamientos, como por ejemplo el argentino ${ }^{11}$, contemplan dos tipos de irregistrabilidades: casos en que se cumplen condiciones negativas de registrabilidad, por una parte y, excepciones a la registrabilidad por la otra. En ambas clases encontramos casos que configuran el dominio público.

Por su parte, la normativa chilena del ramo -Ley de Propiedad Industrial ( $\mathrm{n}^{\circ}$ 19.039- no efectúa tal distinción, y destina el artículo 20 a la enumeración de las causales de irregistrabilidad marcaria. De dicha lista podemos destacar los siguientes casos que vienen a enriquecer el dominio público:

${ }^{10}$ Véase comentario contenido en la nota al pie $\mathrm{n}^{\circ} 8$

${ }^{11}$ La Ley argentina de Marcas que lleva el No 22.362, hace esa distinción en sus artículos 2 y 3 . El artículo 2 consagra casos en que se cumplen condiciones negativas de registrabilidad ("No se consideran marcas y no son registrables: ..."), mientras que el artículo 3 contiene excepciones a la registrabilidad ("No pueden ser registrados: ..."). 
- las denominaciones técnicas o científicas, el nombre de las variedades vegetales, las denominaciones comunes recomendadas por la Organización Mundial de la Salud y aquellas indicativas de acción terapéutica, todos ellos respecto del objeto a que se refieren (letra b);

- las expresiones o signos empleados para indicar el género, naturaleza, origen, nacionalidad, procedencia, destinación, peso, valor o cualidad de los productos, servicios o establecimientos (letra e);

- las que sean de uso general en el comercio para designar cierta clase de productos, servicios o establecimientos (letra e);

- las que no presenten carácter distintivo o describan los productos, servicios o establecimientos a que deban aplicarse (letra e); y

- la forma o el color de los productos o de los envases, además del color en sí mismo (letra i). Sin embargo, si la forma es reivindicable a través de otro derecho intelectual (por ejemplo, diseño o dibujo industrial) debería ser excluido de esta enumeración.

Estimamos que no forman parte del dominio público aquellas marcas que se hayan registrado alguna vez y luego no se han renovado, ni tampoco las expresiones o signos susceptibles de ser registrados como marca y que aún no hayan sido registrados. Tampoco, se incluyen las expresiones o signos que hayan sido solicitadas como marca, pero cuya tramitación luego haya terminado por abandono o desistimiento del solicitante. Asimismo en aquellos países cuyas legislaciones supeditan el registro de las marcas a su uso efectivo, todas aquellas expresiones o signos que no son efectivamente utilizados, tampoco pueden ser considerados dominio público marcario. En todos estos casos, las expresiones o signos pueden en cualquier momento ser extraído de la esfera de libre uso, imponiéndoles exclusividad, al ser usado o solicitado y registrado legítimamente por cualquier persona.

Entre las causales de irregistrabilidad de marcas, encontramos generalmente también aquellas que se refieren a los signos, distintivos, símbolos o punzones oficiales adoptados por un Estado; así como a los escudos, banderas y otros emblemas, denominaciones o siglas de cualquier Estado, de organizaciones internacionales o de servicios públicos estatales ${ }^{12}$. En este caso, si bien estamos frente a una irregistrabilidad, hay que advertir que generalmente el uso exclusivo de dichas expresiones y signos es entregado a entidades públicas o internacionales. Por consiguiente tampoco integrarían el dominio público. Pero en el evento que su uso no sea exclusivo de entidades estatales, puede perfectamente estimarse como un caso de dominio público; ello sería especialmente el caso de los nombres de los Estados, organismos nacionales y organizaciones internacionales.

Cabe tener presente que la mayor o menor extensión del plazo de protección marcaria por parte del legislador no incidirá mayormente en el campo del dominio público, pues las marcas son los únicos derechos de propiedad intelectual que no enfrentan una limitación temporal en cuanto a su protección. En efecto, dado que las marcas

12 El artículo 20 de nuestra Ley de Propiedad Industrial establece dicha causal en sus letras a) y d). 
son renovables indefinidamente en el tiempo, el uso de determinada expresión o signo puede constituirse en una ventaja competitiva perpetua, o "monopolio perpetuo". Incluso puede concebirse el caso que una marca registrada no se renueve, y luego de ser abandonada, vuelva a ser registrada por su antiguo titular o un tercero; con lo cual queda demostrado que la marca liberada no necesariamente conserva dicha condición.

\subsection{EL DOMINIO PÚBLICO EN EL ÁMBITO DE LAS PATENTES}

En el campo de las patentes de invención ${ }^{13}$, el dominio público de un país queda conformado por los siguientes casos:

- Las materias impatentables ${ }^{14}$, siempre que no sean reivindicables a través de otro derecho de propiedad intelectual. Podemos mencionar en este orden de cosas, los descubrimientos, teorías científicas y métodos matemáticos; los modelos económicos, planes y métodos de negocios; los métodos de diagnóstico, terapéuticos y quirúrgicos; y las plantas y animales.

- Las solicitudes de patentes que hayan sido publicadas y luego rechazadas, desistidas o abandonadas en su tramitación, por cualquier causa que sea.

- Las patentes vigentes en países extranjeros y no solicitadas o registradas en nuestro país. Esta causal se debe a la limitación geográfica del derecho de patente.

- Las solicitudes de patentes presentadas en el extranjero, en aplicación a la misma limitación anterior. Para que opere este caso tienen que cumplirse los siguientes requisitos copulativos:

- que la solicitud haya sido publicada,

- que no haya sido presentada o aceptada en el ámbito nacional, y

- que su plazo de prioridad $^{15}$ haya transcurrido, de manera que ya precluyó la posibilidad de obtenerse patente en nuestro país.

- Las patentes cuyo plazo de vigencia ya haya expirado en forma regular en el tiempo (limitación temporal al derecho exclusivo de la patente).

- Las patentes declaradas nulas por sentencia judicial y cuyo registro haya sido cancelado.

\footnotetext{
${ }^{13}$ Lo que señalaremos con respecto a las patentes de invención, será perfectamente aplicable a las demás innovaciones industriales, tales como modelos de utilidad, dibujos y diseños industriales, esquemas de trazado o topografías de circuitos integrados.

14 Nuestra Ley de Propiedad Industrial enumera las causales de impatentabilidad por no constituir invención, en su artículo 37.

Nuestra legislación -al igual que la mayoría de los países del mundo- distingue dos clases de impatentabilidades: casos en que se cumplen condiciones negativas de patentabilidad (exclusiones) y excepciones a la patentabilidad (prohibiciones). Únicamente la primera clase de impatentabilidades constituye fuente del dominio público del conocimiento tecnológico.

15 La prioridad internacional se encuentra contemplada en el artículo 4 del Convenio de París para la Protección de la Propiedad Industrial: "quien hubiere depositado regularmente una solicitud de patente de invención, de modelo de utilidad, de dibujo o modelo industrial, de marca de fábrica o de comercio, en alguno de los paises de la Unión o su causahabiente, gozará, para efectuar el depósito en los otros paises, de un derecho de prioridad", por un plazo de 12 meses para las patentes de invención y modelos de utilidad y de 6 meses para los dibujos o modelos industriales.
} 
- Las patentes caducadas por falta del pago periódico del impuesto o tasa de mantención de la patente, lo cual se produce usualmente:

- por razones propias de la patente, por ejemplo falta de utilidad comercial de la invención protegida u obsolescencia del mismo,

- por razones atribuibles al titular, por ejemplo falta de fondos para su pago.

En este contexto, no hay que confundir el dominio público con la información tecnológica contenida en los documentos de patentes y que, una vez publicada en el marco de la tramitación de una solicitud de patente, es de acceso libre para cualquier persona. Conviene recordar que la obligación jurídica de suministrar una descripción detallada ${ }^{16}$ de la invención, modelo de utilidad o diseño que se desea registrar, busca promover la divulgación de las invenciones e innovaciones industriales, pues son estos antecedentes los que hacen posible el continuo avance del estado de la técnica ${ }^{17}$. En efecto, las patentes no son secretos comerciales o industriales; el inventor consigue protección a través de la patente, solo si hace público su conocimiento técnico. Si bien este conocimiento de acceso público va aumentando el acervo científico, tecnológico y cultural de la sociedad, no puede considerarse de propiedad común, dado que durante un cierto lapso de tiempo es "gravado" con la exclusividad, no pudiendo ser utilizado en forma libre por terceros.

Por otra parte, existen creaciones intelectuales cercanas a las invenciones que no son patentables, pero sí susceptibles de ser resguardados a través de otro derecho de propiedad intelectual, imponiéndose con ello exclusividad en cuanto a su uso. Naturalmente, esas creaciones no serían parte del dominio público universal. Como ejemplo, podemos mencionar los programas computacionales y obras científicas, que por regla general, no son susceptibles de patentamiento, pero sí pueden ser protegidos a través del derecho de autor.

Finalmente pudiera plantearse la duda acerca de dos situaciones especiales: las excepciones del derecho de patente y el agotamiento del derecho de patente ${ }^{18}$. Si bien

\footnotetext{
${ }^{16}$ La solicitud de una patente debe ir acompañada de una hoja técnica en que consta el resumen del invento, de una memoria descriptiva, del pliego de reivindicaciones y de los dibujos técnicos. Especialmente, la memoria descriptiva y los dibujos son los que contienen valiosa información tecnológica, que deberían permitir a un experto con medianos conocimientos replicar la invención y hacerla funcionar.

${ }^{17}$ La Ley 19.039 define el "estado de la técnica" en su artículo 33,' "como todo lo que haya sido divulgado o hecho accesible al público, en cualquier lugar del mundo, mediante una publicación en forma tangible, la venta o comercialización, el uso o cualquier otro medio, antes de la fecha de presentación de la solicitud de patente en Chile o de la prioridad reclamada ... . También quedará comprendido dentro del estado de la técnica, el contenido de las solicitudes nacionales de patentes o modelos de utilidad tal como hubiesen sido originalmente presentadas, cuya fecha de presentación sea anterior ... y que hubieren sido publicadas en esa fecha o en otra posterior".

${ }^{18}$ Las excepciones del derecho de patente y el agotamiento del derecho de patente se encuentran recogidas en nuestra ley en el art. 49, en los siguientes términos:

"El dueño de una patente de invención gozará de exclusividad para producir, vender o comercializar, en cualquier forma, el producto u objeto del invento $y$, en general, realizar cualquier otro tipo de explotación comercial del mismo.

En las patentes de procedimiento, la protección alcanza a los productos obtenidos directamente por dicho procedimiento.
} 
estimamos que en dichos casos no surge un campo de dominio público, ello pudiera ser discutible. En ambas situaciones la ley impide al titular de la patente hacer efectivo sus derechos subjetivos, y como consecuencia de ello se libera una proporción de uso de la patente en favor de la comunidad. Sin embargo, se trata de una limitación al derecho de explotación económica de una patente, el cual por otro lado puede considerarse como indivisible.

\subsection{EL DOMINIO PÚBLICO EN EL ÁMBITO DEL DERECHO DE AUTOR}

En el derecho de autor, el dominio público toma el nombre de "patrimonio cultural común"19. Comúnmente se consideran pertenecientes al dominio público en este ámbito, los siguientes casos:

- creaciones intelectuales no susceptibles de protección, tales como las ideas no expresadas en forma concreta, los procedimientos, métodos de operación y conceptos matemáticos;

- obras autorales cuyo plazo de protección haya expirado en el tiempo;

- obras de autores desconocidos que no pertenezcan a persona determinada, incluyéndose las canciones, leyendas, danzas y las expresiones del acervo folclórico;

- obras de autores fallecidos sin sucesores ni causahabientes;

- obras cuyos titulares renunciaron expresamente a sus derechos y por ende, a la protección legal;

- obras de autores extranjeros, domiciliados en el exterior que no estén protegidos por el sistema de tratados internacionales, y

- obras que fueren expropiadas por el Estado, sin que se haya especificado un beneficiario.

En este contexto, hay que recordar que el hecho de pertenecer una obra al dominio público, no significa la extinción de los derechos morales. El paso de una obra desde un régimen de dominio privado de propiedad intelectual a uno de dominio público, únicamente implica la extinción de los derechos patrimoniales para su (último) titular. Los derechos morales son por esencia derechos perpetuos, inalienables, imprescriptibles

El alcance de la protección otorgada por la patente o la solicitud de patente se determinará por el contenido de las reivindicaciones. La memoria descriptiva y los dibujos servirán para interpretar las reivindicaciones.

El derecho de patente se extenderá a todo el territorio de la República hasta el día en que expire el plazo de concesión de la patente.

La patente de invención no confiere el derecho de impedir que terceros comercialicen el producto amparado por la patente, que ellos hayan adquirido legitimamente después de que ese producto se haya introducido legalmente en el comercio de cualquier pais por el titular del derecho o por un tercero, con el consentimiento de aquel.

La patente de invención no confiere el derecho de impedir que terceros importen, exporten, fabriquen o produzcan la materia protegida por una patente con el objeto de obtener el registro o autorización sanitaria de un producto farmacéutico. Lo anterior no faculta para que dichos productos sean comercializados sin autorización del titular de la patente".

${ }^{19}$ En Chile, la Ley 17.336 de Propiedad Intelectual enumera en su artículo 11, las obras que se consideran pertenecientes al "patrimonio cultural común". 
e irrenunciables, que constituyen una clara manifestación del nexo indisoluble entre el autor y su obra, y que comprometen al público en general. Este punto resulta particularmente interesante en el caso antes enumerado de las "obras cuyos titulares renunciaron expresamente a sus derechos": esta renuncia ha de entenderse restringida a los derechos patrimoniales, sin que pueda comprender derechos morales.

Algunos países, como Bolivia, disponen de dos clases de acervo común de obras, uno nacional y otro extranjero. En efecto, el "Patrimonio Nacional" es el régimen al que pasan las obras de autores nacionales que salen de la protección del derecho patrimonial privado, por cualquier causa. Se incluye en ese concepto las obras del folclore, que se consideran propias del patrimonio cultural tradicional de la nación. En cambio, pertenecerían al "dominio público", las obras extranjeras cuyo período de protección esté agotado ${ }^{20}$.

\subsection{COMENTARIOS COMUNES AL DOMINIO PÚBLICO EN EL ÁMBITO DE LAS PATENTES Y DEL DERECHO DE AUTOR}

A estas alturas el lector podrá haber detectado similitudes en la configuración del dominio público de las patentes y del derecho de autor. En efecto, existen varias que trataremos de comentar a continuación.

A diferencia de lo que sucede con las marcas comerciales, la utilización del concepto de dominio público resulta muy natural y usual en la esfera de las patentes de invención y de los derechos de autor. Ello se debe a que en esos dos ámbitos el significado y la extensión del dominio público resulta ser fundamental, por un lado para el avance de las ciencias y de la tecnología, y por el otro, para el progreso de niveles culturales y educacionales de un país.

Asimismo podemos agregar que en ambos casos, una parte significativa del dominio público está compuesta por conocimientos u obras cuya protección legal ya ha expirada, fenómeno que a menudo recibe el nombre de "liberación de conocimiento".

Deseamos hacer hincapié en que la determinación de los plazos de protección legal de las patentes y del derecho de autor, influyen en forma directa en cuan extenso será el campo del dominio público. El período de protección de los derechos autorales es más extenso y más incierto que el de los derechos de patente, lo cual pudiera inducir a pensar que el dominio público industrial es más amplio que el cultural. Sin embargo, ello tiene su explicación en que las obras autorales se originan a partir de la personalidad de su creador. Se trata de una originalidad que es de carácter subjetivo y que no pierde su vigencia en el tiempo de vida del autor. El vínculo espiritual estrecho entre autor y obra se mantiene a través de los derechos conferidos (especialmente morales), durante toda la vida de aquel, e incluso más allá de su muerte, transmitiéndose a los herederos. Por lo mismo, si el creador es una persona natural, la duración de la protección es incierta, por estar ligada a la vida de la persona. Por el contrario, en materia de patentes se atiende a ciclos de vida de productos y procedimientos que son más cortos. Las invenciones patentadas a su vez sirven para

${ }^{20}$ En tal sentido, artículos 21, 22 y 58 de la Ley 1.322 de Derecho de Autor de Bolivia, aprobada el año 1992. 
seguir desarrollando adelantos en base a ellas, los cuales producirán la obsolescencia de las primeras. En consecuencia, no se requiere, ni es deseable que la ley otorgue plazos prolongados de exclusividad, que tendrían por efecto el frenar el desarrollo de nuevas invenciones o de mejoras de invenciones existentes ${ }^{21}$.

Deseamos destacar que por regla general impera una connotación universal del concepto de dominio público, no limitándose a países determinados. En ese sentido, esta noción se concilia armónicamente con la del "estado de la técnica". Ambos conceptos se refieren a un acervo universal; sin embargo el estado de la técnica es por un lado más restringido ya que se limita al conocimiento técnico industrial, y por otro más amplio al incluir tanto patentes ya expiradas o caducadas como las que aún se encuentran vigentes.

\section{CONFLICTO DE INTERESES EN MATERIA DE PROPIEDAD INTELECTUAL}

Como sucede con frecuencia en el derecho económico - pero no solo en esa rama del derecho- el tema en estudio no es sino una manifestación de una contraposición de intereses, que adopta denominaciones genéricas muy diversas. Es así como podemos configurar el siguiente esquema, en que asignamos diversos conceptos alternativos que se adscriben a los intereses representados por la "propiedad intelectual" y el "dominio público de la propiedad intelectual":

\begin{tabular}{|l|l|}
\hline Propiedad Intelectual & Dominio Público de la Propiedad Intelectual \\
\hline - Derechos personales & - Derechos sociales \\
- Función individual de la propiedad & - Función social de la propiedad \\
- Bien individual & - Bien común \\
- Dominio o propiedad privada & - Dominio público o propiedad colectiva \\
- Interés privado o personal & - Interés público o colectivo \\
- Fines personales & - Fines sociales \\
\hline
\end{tabular}

El lector reconocerá muchos de estos términos propios del conflicto de intereses que se suscita en materia del derecho de propiedad (material o tradicional) ${ }^{22}$, y podrá darse cuenta que en materia de propiedad intelectual se repite la tensión entre el titular y la sociedad, puesto que en ambos casos no estamos frente a derechos absolutos.

Se trata aquí de una tensión entre diversas fuerzas y que representan derechos y objetivos muy legítimos, aisladamente considerados, pero cuya conciliación se dificulta en la práctica. ¿Cuáles son esos derechos y objetivos? Siguiendo con la representación anterior, podemos adjudicar a cada posición, los siguientes objetivos ${ }^{23}$ :

${ }^{21}$ En base a: SCHMiTZ (2006) p. 21.

22 Basta pensar solo en los conflictos de intereses que se dan en el caso de expropiaciones, tanto las propiamente tales como las impropias.

${ }^{23}$ Basado en WORLDWIDE ACADEMY (2008) módulo 1, pp. 81 y 82. 


\begin{tabular}{|c|c|}
\hline $\begin{array}{l}\text { Interés individual del titular de propie- } \\
\text { dad intelectual }\end{array}$ & Intereses de la sociedad \\
\hline $\begin{array}{l}\text { - Recompensar la innovación, creativi- } \\
\text { dad e inversión productiva privada } \\
\text { - Recompensar el esfuerzo material y } \\
\text { moral, dedicación, tiempo, etc. in- } \\
\text { vertido en la creación o generación } \\
\text { de obras o producciones industriales } \\
\text { - Reconocer los derechos individuales } \\
\text { de creadores, inventores y autores, en } \\
\text { relación a una explotación pacífica y } \\
\text { efectiva del resultado creativo o in- } \\
\text { ventivo } \\
\text { - Acceso a conocimientos y al estado } \\
\text { de las ciencias y tecnologías para ge- } \\
\text { nerar nuevas creaciones e innovacio- } \\
\text { nes productivas (en este punto hay co- } \\
\text { incidencia de intereses con los de la } \\
\text { sociedad) } \\
\text { Reconocimiento moral y honor } \\
\text { como creador/inventor }\end{array}$ & $\begin{aligned} & \text { - } \text { Fomentar la innovación, creatividad } \\
& \text { e inversión productiva privada } \\
& \text { - } \\
& \text { Asegurar la libertad de expresión, la } \\
& \text { conservación de las obras culturales y } \\
& \text { el acceso a las mismas } \\
& \text { - } \text { Velar por la circulación de la infor- } \\
& \text { mación y el acceso a la tecnología, } \\
& \text { así como por la divulgación pública } \\
& \text { del estado de las ciencias y tecnolo- } \\
& \text { gías } \\
& \text { - Aumentar los intercambios comercia- } \\
& \text { les y culturales con otras naciones } \\
& \text { - Atraer la inversión y la tecnología ex- } \\
& \text { tranjeras } \\
& \text { - Cumplir las normas y estándares in- } \\
& \text { ternacionales y solucionar las contro- } \\
& \text { versias } \\
& \text { - Contribuir al desarrollo económico, } \\
& \text { cultural, científico y social del país }\end{aligned}$ \\
\hline
\end{tabular}

En general esos derechos y objetivos no son difíciles de reconocer y para la mayoría de las personas pueden resultar bastante lógicas. Sin embargo, la contraposición de intereses se vuelve un problema de mayor complejidad, especialmente con la intervención de intermediarios entre los creadores/inventores y la sociedad. Se trata de grandes empresas, muchas veces multinacionales, tales como editoriales, sellos musicales, compañías farmacéuticas, etc., que adquieren los derechos de propiedad intelectual y luego se encargan de la producción en serie y comercialización de las obras o invenciones. Son estas las entidades encargadas de la difusión de la creación o innovación intelectual, lo cual en sí ya requiere de cuantiosas inversiones en publicidad, marketing y estrategias de comercialización. Lo anterior evidentemente se desarrolla en un ambiente altamente competitivo de los mercados globales.

En realidad, la diversidad de intereses y objetivos descritos es la que constituye el telón de fondo de las discusiones sobre los pros y contras de la propiedad intelectual. Estas controversias sobre el sistema de propiedad intelectual tienen carácter transversal en todo sentido: geográfica, histórica e ideológicamente. 
Desde un punto de vista geográfico, estas discusiones están presentes prácticamente en todos los países, y se repiten además en los foros internacionales ${ }^{24}$. En un sentido histórico, podemos sostener que desde los inicios de la propiedad intelectual en el siglo $\mathrm{XIX}^{25}$ hasta nuestros días somos testigos del choque de opiniones entre partidarios y opositores del sistema de propiedad intelectual. Además en la controversia intervienen juristas, economistas y políticos al mismo tiempo, lo cual ya demuestra que en el tema inciden aspectos jurídicos, económicos, políticos, y sociales. Precisamente por esta razón, y dado que se excede el campo de la doctrina jurídica, caracterizamos esta discusión como de tipo ideológica.

\subsection{Posiciones Ideológicas de La CONTROVERSia}

Con lo descrito en el punto anterior, podemos pasar a analizar las posiciones ideológicas involucradas en esta discusión.

La búsqueda de un equilibrio de intereses entre el bien individual y el bien común, como solución a la controversia planteada, es una cuestión inherente a todo derecho de propiedad, sea que este recaiga sobre bienes tangibles, o como en este caso sobre intangibles. Así, los partidarios de un sistema fuerte y garantista de propiedad intelectual promoverán el interés individual del titular del derecho de propiedad privada. No hay que perder de vista que en virtud de la intermediación antes explicada, este titular será por regla general una empresa, en especial si se trata de derechos intelectuales

${ }^{24}$ En ese contexto, recordemos que desde ya algunos años se encuentra instalada en el seno de la Organización Mundial de Propiedad Intelectual, una comisión llamada "Agenda de Desarrollo", que debate acerca de cómo organizar el sistema de forma más amigable para los países económicamente menos desarrollados. Particularmente, Argentina y Brasil han trabajado activamente en dicha comisión que se originó a través de la "Declaración de Ginebra sobre el futuro de la OMPI", adoptada el 4 de octubre de 2004 por la Asamblea General de la Organización Mundial de la Propiedad Intelectual (OMPI).

25 En los primeros tiempos de la propiedad intelectual se pueden encontrar varios cuestionamientos al naciente sistema de patentes. Al efecto, la siguiente lista servirá de ejemplo:

- 1851: el Parlamento británico y la Comisión Real señalaron problemas en el funcionamiento del sistema de patentes.

- 1854: en Holanda, la Comisión de Desarrollo Industrial publica un informe crítico sobre el sistema de patentes.

- 1857: en Gran Bretaña, la Conferencia de Ciudadanos para el Desarrollo de las Ciencias Sociales se reúne en el marco de la "Asamblea anual de Reforma y Abrogación de patentes".

- 1863: el Congreso de Economistas Alemanes declara que "las patentes de invención son perjudiciales para el bien común”.

- 1863: el Parlamento suizo rechaza en dos oportunidades un proyecto de ley sobre patentes.

- 1868: el Presidente del Comité Técnico de la Conferencia alemana de Economía Nacional recomienda abolir el derecho de patentes.

- 1869: los Países Bajos derogan el sistema de patentes.

- 1869: la Cámara de Comercio de Leipzig, Alemania demanda la eliminación del sistema de patentes.

Fuente: SUZUKI (2008) p. 3 [Traducción libre del Autor]

En el mismo sentido, Zuccherino señala: "En el pasado, se ha cuestionado por parte de cierta doctrina, la existencia de un sistema normativo de patentes de invención. Dichas corrientes de pensamiento originaron, en ciertas circunstancias, situaciones de carencia de una adecuada legislación al respecto".

Fuente: ZUCCHERINO (1995) p. 20.

Además sobre el tema, véase: SCHMITZ (2006) 
de alto valor económico. En cambio, los opositores a tal sistema promueven la función social de la propiedad privada, lo cual en materia de propiedad intelectual generalmente significa fortalecer el dominio público.

Ya hemos señalado que la discusión en torno al equilibrio de intereses pertenece a uno de los temas más controvertidos de la propiedad intelectual, interviniendo en el debate tanto juristas como economistas. Tanto en el mundo jurídico como en el mundo económico encontramos muchas veces corrientes contrapuestas. Por un lado, existen quienes instan a ampliar el campo de acción de la propiedad intelectual, incluso apoyando la extensión de los derechos personales en desmedro del dominio público. Los partidarios de dicha corriente la componen juristas de tendencia económica liberal, y los representantes de sectores empresariales y de sus asociaciones gremiales. El argumento fundamental y lógico que se esboza es el siguiente: para que haya inversión en investigación y desarrollo y en la creación de obras autorales, es indispensable "premiar" el esfuerzo investigador y creador mediante la exclusividad de derechos de explotación durante un tiempo suficiente para recuperar la inversión y obtener una ganancia legítima. Entonces, "más propiedad intelectual significa más desarrollo, como resultado de mayores flujos de inversión directa extranjera, transferencia de tecnología y de mayores incentivos para la innovación local"26. O en otras palabras: "entre mayor sea el alcance asi como la duración de los derechos de propiedad del creador, mayor será el incentivo para la creación de ideas y menor el incentivo para difundirlas y aplicarlas" 27 . En el plano internacional se llega a establecer una correlación entre desarrollo económico y protección severa de los derechos de propiedad intelectual: “... los paises con economías avanzadas tienden a ser aquellos que despliegan sistemas de propiedad intelectual en los que el público tiene un grado básico de confianza. ... son razonablemente efectivos en salvaguardar la innovación y la expresión creativa. Inversamente, los paises que se encuentran en diversos grados de desarrollo tienden a tener sistemas de protección de la creatividad intelectual en los cuales sus poblaciones no depositan mucha confianza"28.

Por el otro lado, se encuentra una importante tendencia académica principalmente norteamericana (James Boyle, U. de Yale; Lawrence Lessig, U. de Stanford; Michael Geist, U. de Ottawa; Bernt Hugenholtz, U. de Amsterdam), representada en otros países fundamentalmente a través de académicos y organizaciones no gubernamentales, quienes adoptan posiciones críticas frente al actual sistema de la propiedad intelectual. Ello, muchas veces se presta para confusiones y malentendidos, en el sentido de identificar esta postura como partidaria del no respeto e incumplimiento de la ley, o incluso promotora de la piratería de los bienes protegidos por derechos de propiedad intelectual. Por ello, esta corriente se encarga de aclarar desde la partida que también ellos favorecen el respeto irrestricto de las leyes de propiedad intelectual, pero que estas requieren ser rediseñado de forma más justa para todos los estamentos

\footnotetext{
26 CORREA (2005) p. 15.
}

Hacemos presente que el texto citado, continúa: "Esta simple vinculación, empero, no tiene base teórica ni empirica suficiente. ...”.

27 CoOTer y Ulen (1998) p. 169.

28 SHERWOOD (1992) p. 13. 
de la sociedad civil. El sistema actual se encuentra excesivamente al servicio de los intereses económicos individuales de los titulares, los cuales en la mayoría de los casos son empresas multinacionales, y de esta forma se estaría amparando los intereses económicos de países económicamente desarrollados.

Así, los autores pertenecientes al área económica se encuentran ante un trade-off por varias razones. En primer lugar ante el continuo desarrollo de tecnologías modernas en el campo de la informática y de las telecomunicaciones (las llamadas "TIC's") -máquinas fotocopiadoras, grabadoras y reproductoras de sonido e imágenes, inicialmente analógicas y luego digitales, etc.- se hace "cada vez más difícil la protección de las formas más convencionales de propiedad intelectual". Lo anterior ha llevado a formular la siguiente pregunta: “iNo será que, en lugar de considerar reformas para fortalecer las patentes y copyrights, deberiamos movernos en la dirección contraria?" 29 . En ese mismo sentido se llega a argumentar que solo la adaptación del derecho a las nuevas tecnologías, y específicamente la utilización de herramientas jurídicas eficaces, permiten enfrentar las mayores facilidades para piratear creaciones intelectuales.

Relacionado con este argumento, y siguiendo las ideas de Cole, la teoría económica tradicionalmente le ha dado cabida a la propiedad privada en relación a la escasez. En otras palabras, "la propiedad privada garantiza que los bienes escasos serán usados de la forma más eficiente y productiva”. Por el contrario, si un bien se encuentra disponible en abundancia e ilimitadamente no se justifica limitar el acceso y la disposición del mis$\mathrm{mo}^{30}$. Precisamente eso es el caso de las creaciones intelectuales modernas, cuya difusión y reproducción tienen costos marginales insignificantes. Con ayuda de las nuevas tecnologías se ha logrado vencer la escasez natural originada en costos. Sin embargo, subsiste el sistema jurídico tradicional de la propiedad intelectual, y es más, en las últimas décadas, el nivel regulatorio se ha ido incrementando, de tal manera que el campo sujeto al derecho de la propiedad intelectual se agranda cada vez más, en desmedro de la porción que corresponde al dominio público.

Con lo anterior, queda claro el dilema de los economistas: defender irrestrictamente al mercado y a sus leyes implica rechazar la creación artificial de escasez y monopolios temporales (impuestos por las leyes de propiedad intelectual), como sucede con los bienes intelectuales protegidos, pero por otra parte ello no se condice con la defensa de la libertad y propiedad individual.

Por último, hay quienes dentro de esta corriente impulsan un vasto campo del dominio público, dado que solo de esta forma se dará acceso masivo en forma gratuita a educación, al conocimiento y a la cultura, lo cual se considera especialmente necesario respecto de sectores de la población que no disponen de las condiciones socioeconómicas para solventar dicho acceso. En otras palabras, se trata de un argumento de índole social tendiente a crear igualdad de oportunidades entre todos los integrantes de la comunidad.

${ }^{29}$ COLE (2003) p. 35 y sgtes.

${ }^{30} \mathrm{Al}$ respecto, recordemos la existencia de los llamados "bienes libres", como el aire, los que se contraponen a los bienes económicos. 
En nuestro país, las posiciones ideológicas no se han perfilado tan claramente. Por un lado, resulta difícil no percatarse de los innumerables llamados y campañas de los más diversos sectores (gobiernos de naciones económicamente desarrollados, académicos, estudios jurídicos especializados en propiedad intelectual, empresarios y sus asociaciones gremiales, etc.), que exigen al Gobierno o que promueven ante otras instancias, la aplicación de políticas más severas y claras en pro de la defensa de los derechos de propiedad intelectual ${ }^{31}$.

31 Solo para ejemplificar podemos enunciar los siguientes titulares de prensa publicados en los últimos tiempos:

- "Polémica por posible cobro a proveedores de Internet por descargas musicales", Diario Financiero, 16 de octubre de 2008

- "Vienen cambios a leyes de propiedad intelectual en Chile: Modificaciones pondrán las regulaciones más en línea con exigencias del gobierno estadounidense", artículo del Economist Intelligence Unit, Diario Financiero, 30 de enero de 2008

- "ACTI [Asociación Chilena de Empresas Tecnológicas de Información]: proyecto antipiratería incumple TLC con EE.UU.: en la ingeniería inversa se centra uno de los tres reparos que la industria hace a la iniciativa", 31 de diciembre de 2007

- "Proyecto de propiedad intelectual en la mira de los Estados Unidos: La Oficina de la Representante de Comercio de Estados Unidos y la Direcon realizarán una videoconferencia para analizar la iniciativa", Diario Financiero, 14 de diciembre de 2007

- "Las drásticas medidas que adoptaron en Europa para terminar con la piratería: cortar acceso a internet y subir el precio de un IPod son las más emblemáticas", Diario Financiero, 29 de noviembre de 2007

- "Cámara Chilena del Libro arremete por una nueva ley", Diario Financiero, 19 de enero de 2007

- "UE destacó a Chile dentro de países con alta piratería", Diario Financiero, 6 de octubre de 2006

- "Primer Secretario de Asuntos Económicos: EE.UU. advierte a Chile que cae la inversión en el país por la ley de propiedad industrial", El Mercurio, 7 de septiembre de 2006

- "Presidente de ASIMCO [Asociación de Importadores de Perfumes y Cosméticos] demanda mayor fiscalización a las autoridades: Piden más control de piratería de perfumes y cosméticos", Diario Financiero, 18 de julio de 2006

- "Iniciativa mundial incluye acciones para hacer cumplir legislación: UE y EE.UU. lanzan plan contra robo de propiedad intelectual", Diario Financiero, 21 de junio de 2006

- "Bachelet en EE.UU.: firmas norteamericanas en Chile hablan sobre propiedad intelectual", El Mercurio, 8 de junio de 2006

- "John Murphy lanzó duras acusaciones: el país infringe estado de derecho. Comercio de EE.UU. en contra de Chile por propiedad intelectual", Diario Financiero, 24 de mayo de 2006

- "Propiedad intelectual: Mayor gremio de EE.UU. ataca a Chile por pugna de patentes", El Mercurio, 24 de mayo de 2006

- "Solicitud de la Alianza Internacional de Propiedad Intelectual al gobierno norteamericano: Firmas de EE.UU. piden subir control de propiedad intelectual en Chile”, La Tercera, 21 de febrero de 2006

- "El Embajador Craig Kelly se refiere a las excelentes relaciones con Chile: Propiedad Intelectual e inversión, entre las deudas del TLC con EE.UU.", Diario Financiero, 17 de febrero de 2006

- "Embajador Kelly comunicó las preocupaciones de Washington sobre el tema: EE.UU. entrega a Chile decálogo para proteger la propiedad intelectual”, Diario Financiero, 29 de septiembre de 2005

- "UE está inquieta por propiedad intelectual", Diario Financiero, 19 de mayo de 2005

- "IFPI Chile [Asociación Internacional de Productores Fonográficos de Chile]: 50\% del mercado de la música en nuestro país es ilegal: Industria chilena solicitó a EE.UU. hacerse parte en problema de piratería", Diario Financiero, 17 de mayo de 2005

- "Estados Unidos califica de 'dramático' el alza de la piratería en Chile", Diario Financiero, 3 de mayo de 2005

- "Comisión de la UE propone más capacitación: Piden normas adecuadas para combatir piratería", Diario Financiero, 5 de abril de 2005 
En contraposición a esta corriente parecen aisladas las voces que consideran que el problema primordial no radica en el incumplimiento de las leyes, sino que en la falta de equidad y equilibrio de las normas de propiedad intelectual. Representan esta opinión en nuestro país, centros de estudio y organizaciones no gubernamentales centrados en el ámbito de los derechos de autor, específicamente en la necesidad de acceso al conocimiento y a la cultura ${ }^{32}$.

Podemos observar que las opiniones frecuentemente se tienden a simplificar, al distinguir sencillamente entre los defensores de la propiedad intelectual y partidarios del dominio público; sin embargo no hay que olvidar que existen muchas posturas intermedias con matices muy diversos en las opiniones.

\subsection{SOlución de la CONTROVERSIA: EL EQUilibrio DE INTERESES}

Al igual como sucede en el caso de la propiedad tradicional o material, la solución al conflicto en la propiedad intelectual debe buscarse en un equilibrio de intereses. Equilibrio de intereses implica en todo caso una decisión política, que debe traducirse en lo jurídico, llevando a una conciliación de las posiciones entre el bien individual originado en los derechos intelectuales adquiridos y el bien común derivado del uso del patrimonio común o dominio público.

Desde los comienzos históricos de la propiedad intelectual, se ha planteado la necesidad de la existencia de dicho equilibrio de intereses, y así aparece enunciado en numerosos de tratados internacionales ${ }^{33}$. La revisión del justo equilibrio debe ser perma-

- "Karl Falkenberg, personero de la UE habla además del uso de la denominación de origen: Chile necesita mejorar la aplicación de los derechos de propiedad intelectual", Diario Financiero, 20 de diciembre de 2004

- "Inquieta el respeto a la propiedad intelectual: UE no quiere que sus empresas sean discriminadas en Chile", Diario Financiero, 16 de diciembre de 2004

- "En el marco del II Comité de Asociación del Acuerdo entre Chile y el Bloque Europeo: Delegación de la UE viene a revisar protección de propiedad intelectual", Diario Financiero, 13 de diciembre de 2004

- "Propiedad industrial: la deuda todavía pendiente con el mundo", Diario Financiero, 3 de septiembre de 2004

- "Piratería, EE.UU. y la Unión Europea exigirán respetar la propiedad intelectual: El inminente round del Gobierno", El Mercurio, 17 de agosto de 2003.

$32 \mathrm{Al}$ respecto podemos nombrar en Chile, de manera meramente ejemplar entidades, tales como el Centro de Estudios en Derecho Informático (CEDI) de la Universidad de Chile, las ONG's Derechos Digitales, Alianza Chilena por un Comercio Justo y Responsable (ACCJR).

${ }^{33}$ Los tratados usualmente enuncian en su preámbulo, intenciones que hacen referencia al equilibrio. Algunos ejemplos:

- El Tratado de la OMPI sobre Derecho de Autor (WCT) en su preámbulo, expresa: "Las Partes Contratantes, ... Reconociendo la necesidad de mantener un equilibrio entre los derechos de los autores y los intereses del público en general, en particular en la educación, la investigación y el acceso a la información, como se refleja en el Convenio de Berna,...".

- El Tratado de la OMPI sobre Interpretación o Ejecución y Fonogramas (WPPT) mantiene casi la misma redacción: "Las Partes Contratantes, ... Reconociendo la necesidad de mantener un equilibrio entre los derechos de los artistas intérpretes o ejecutantes y los productores de fonogramas y los intereses del público en general, en particular en la educación, la investigación y el acceso a la información, .... ."

- El preámbulo del Capítulo 17 del Tratado de Libre Comercio entre Chile y Estados Unidos de América establece: "Las Partes, ... Enfatizando que la protección y observancia de los derechos de propiedad intelectual es un principio fundamental de este Capitulo que ayuda a promover la innovación tecnológica, así como la 
nente en el tiempo. Día a día aparecen nuevas tecnologías, nuevas cuestiones que a menudo exigen redefinir el sistema. Para ello basta solo pensar en el surgimiento de Internet, que motivó el inicio de un largo proceso de búsqueda de un nuevo equilibrio, que se tradujo en reformas de normas nacionales e internacionales (Digital Millenium Copyright Act -DMCA-, Tratados de la OMPI sobre Derechos de Autor y sobre Derechos Conexos - WCT y WPPT). Lessig generaliza este proceso con estas palabras: " $\mathrm{La}$ historia del derecho estadounidense ha sido un proceso de equilibrio. Conforme nuevas tecnologias han cambiado la manera en la que se distribuian los contenidos, las leyes se ajustaron, después de un tiempo, a la nueva tecnología. En este ajuste las leyes buscaban asegurar los derechos legitimos de los creadores, al tiempo que protegían la innovación. A veces esto ha significado más derechos para los creadores y a veces menos" ${ }^{34}$. La generación de dicho equilibrio permanente en el tiempo - por cierto difícil de lograr- es el que asegura el desarrollo económico y el bienestar social de las naciones.

En este sentido, conviene seguir teniendo presente el trasfondo de la discusión y el objetivo antes enunciado: ¿cómo logramos incentivar la innovación en nuestro país, de forma de contribuir efectivamente al desarrollo económico? Inclinar la balanza a favor de uno u otro lado implica poner en peligro el logro de dicho objetivo. Efectivamente, si adoptamos posiciones extremas se provoca el efecto contrario al deseado, esto es impedir o desincentivar la investigación y desarrollo en el futuro ${ }^{35}$. En efecto, si por un lado se otorgan amplísimos plazos de protección de los derechos intelectuales, sin contemplar exclusiones, limitaciones ni excepciones, actuamos en desmedro de la comunidad y de nuevos investigadores, y por el otro si derechamente optamos por la no protección legal de la propiedad intelectual, estamos quitando toda recompensa al esfuerzo creativo-inventivo.

Anteriormente hemos visto que las posiciones ideológicas se encuentran representadas en una forma muy distinta; en nuestro país la discusión pública se centra en la necesidad del reforzamiento del respeto de las leyes de propiedad intelectual y el combate de la piratería. De tal manera, pareciere que únicamente con hacer cumplir la ley ya lograríamos promocionar la investigación y desarrollo, alcanzando con ello los niveles deseados de innovación. Pero queda de lado la necesidad de un equilibrio entre intereses individuales de los titulares de propiedad intelectual y los de la sociedad. Se echa de menos un debate público acerca de sí acaso nuestra ley considera equitativamente los intereses de todos los actores involucrados en la propiedad intelectual.

transferencia y difusión de tecnología para el mutuo beneficio de los productores y usuarios de tecnología, y que incentiva el desarrollo del bienestar social y económico; ... Reconociendo la necesidad de lograr un equilibrio entre los derechos de los titulares y los legitimos intereses de los usuarios y de la comunidad en relación con las obras protegidas; ...".

- El Acuerdo sobre los Aspectos de los Derechos de Propiedad Intelectual relacionados con el Comercio (ADPIC) toca el tema entre sus disposiciones iniciales: "La protección y la observancia de los derechos de propiedad intelectual deberán contribuir a la promoción de la innovación tecnológica y a la transferencia y difusión de la tecnología, en beneficio recíproco de los productores y de los usuarios de conocimientos tecnológicos y de modo que favorezcan el bienestar social y económico y el equilibrio de derechos y obligaciones" (art. 7).

${ }^{34}$ LESSIG (2004) p. 74.

35 Basado en: SCHMitz (2005) p. 31 y ss. 
En la actualidad pareciere haber caído en olvido el rol y la importancia del dominio público en la generación de nuevas creaciones e invenciones. Generalmente, cuando se menciona el dominio público, se piensa en el "uso pasivo de derechos intelectuales" por parte de la sociedad, el cual posee escasa importancia económica. Sin embargo, existe igualmente un "uso activo de los derechos intelectuales" que se atribuye a investigadores, inventores, científicos, creadores, empresas, y que siendo de gran relevancia económica, conduce a las tan deseadas innovaciones y nuevas creaciones. Desde este punto de vista, cobra importancia un acceso libre y gratuito a conocimientos necesarios para generar dichas innovaciones, ya que de otra forma se pierde competitividad e incentivo y se encarecen los costos del desarrollo innovativo.

En este mismo contexto, hay que dejar establecido la valiosa contribución del mismo sistema de patentes (vigentes), que puede considerarse como un inicio de solución equilibrada al exigir al inventor la revelación de su conocimiento y su divulgación pública, mientras que el Estado le otorga una protección temporal que le permite la explotación de su invención en términos de exclusividad ${ }^{36}$. Evidentemente este sistema tan antiguo cumple una utilidad inmensa y un rol insustituible en la difusión del estado de la técnica alrededor del globo, pero el uso comercial de ese tipo de conocimientos, por pequeño que sea e incorporado en nuevas innovaciones, no es gratuito (se requiere licencias que especialmente para pequeños inventores o empresas de países en desarrollo pueden constituir una barrera de costos infranqueable a la hora de querer comercializar sus invenciones que se basan en otras preexistentes); y es más su uso con fines económicos puede ser incluso completamente negado por sus titulares basado en razones competitivas, estratégicas u otras.

El olvido de la relevancia del dominio público, anteriormente aludido, queda de manifiesto desde un punto de vista legislativo, cuando observamos que desde años estamos viviendo una tendencia hacia mayores niveles de protección legal de la propiedad intelectual, promovidos especialmente por el Gobierno de los EE.UU. de América. Es así como algunas corrientes han hablado de la tendencia de la privatización de la vida y del conocimiento ${ }^{37}$, por la cual se permite la apropiación por unos pocos de lo que durante siglos se consideraba perteneciente a todos.

En el pasado hemos presenciado diversas manifestaciones en tal sentido: la expansión del derecho de autor hacia nuevas obras no cubiertas; la implementación de patentes de software; la admisión de patentes relativas a animales, diversas formas de vida y genes humanos; el patentamiento de métodos de negocios y comercialización; la amplia-

\footnotetext{
36 Considerando esta utilidad recíproca, tanto para inventor como la sociedad, pudiera casi llegar a sostenerse que el antagonismo de intereses de la propiedad intelectual no existe, ya que en este caso más bien existe una complementariedad de intereses.

Lo mismo se observa al contrastar los intereses de todos aquellos que le dan un uso activo a los derechos intelectuales (investigadores, creadores, inventores) con los de la sociedad; ambos estamentos buscan un fluido y libre acceso al conocimiento técnico y cultural.

37 Véase al respecto las siguientes obras:

- Ediciones Fundación Vía Libre (2007)

- BOYLE (2003).
} 
ción de los plazos de protección del derecho de autor. El caso chileno en este último punto es ilustrativo: al aprobarse en 1971, la ley del ramo ( $\mathrm{n}^{\circ}$ 17.336), el plazo de protección autoral era de 30 años, luego fue aumentado a 50, y actualmente es de 70 años. De esta forma, la expansión de la propiedad intelectual, a la mano del derecho de autor y de patentes, ha significado una reducción continua del campo del dominio público durante las últimas décadas.

¿Cuáles han sido los efectos de esta desviación en la búsqueda del equilibrio de intereses? La respuesta a esa pregunta está vinculada con la función que cumple el dominio público en favor del avance científico y cultural de la humanidad, tema tocado ya con anterioridad. Cabe entonces preguntarse en qué medida ya ha sido afectado el progreso de la humanidad debido a políticas excesivamente pro propiedad intelectual y afanes desmedidos en la búsqueda de nuevos negocios. Hoy en día en Estados Unidos, ya resulta ser la regla (y no la excepción) que para poder comercializarse una invención patentada se requiere obtener autorizaciones de otros titulares de patentes relacionadas $^{38}$. En definitiva, ese fenómeno - perfectamente aceptable desde una perspectiva jurídica- está conduciendo a una intensa red o maraña de relaciones interdependientes entre titulares de patentes, con los consiguientes costos e ineficiencias económicas.

En relación a las ideas vertidas, estimamos que una solución a la controversia tiene que considerar una consagración legal integral, lo que quiere decir que sin desconocer lo imprescindible que resulta la protección constitucional y legal de los derechos personales (dominio privado) -tal como sucede en la actualidad- también requerimos que el dominio público sea contemplado en forma expresa en el ordenamiento jurídico, y no únicamente a través de disposiciones legales implícitas que regulan plazos, excepciones y limitaciones de derechos intelectuales. Precisamente es esta la forma seguida por la Declaración Universal de Derechos Humanos adoptada por la Organización de las Naciones Unidas en 1948, al plantear un principio de equilibrio. En efecto, el artículo 27 de dicho documento, consagra explícitamente el derecho del autor, y asimismo el derecho a la cultura como un derecho humano al afirmar que:

"1. Toda persona tiene derecho a participar libremente en la vida cultural de la comunidad, a gozar de las artes y a participar en el progreso científico y de los beneficios que resulten.

2. Toda persona tiene derecho a la protección de los intereses morales y materiales que le correspondan por razón de las producciones científicas, literarias o artísticas de las que sea autora”.

La aparente contradicción entre el primero y segundo derecho de este precepto hay que entenderla como un imperativo a lograr el equilibrio entre esos valores a la hora

\footnotetext{
${ }^{38}$ Esto se conoce como "Libertad de Acción", término que designa la posibilidad de explotar comercialmente una invención que fue protegida por una patente, sin infringir los derechos de titulares de otras patentes preexistentes. Generalmente, la libertad de acción se adquiere solicitando licencias a los otros titulares. En ese contexto, resulta frecuente que se lleguen a otorgar licencias cruzadas entre los titulares de patentes que protegen tecnologías relacionadas entre sí.
} 
de elaborar las leyes y tratados para la protección de los derechos intelectuales. En definitiva, el equilibrio se hará efectivo mediante una cuidadosa regulación de plazos de protección de los derechos intelectuales, de las exclusiones, excepciones y limitaciones, pero también a través del establecimiento de una consagración constitucional o legal del dominio público.

\section{CONCLUSIONES}

Indudablemente, la creación de tecnologías, producto de labores de I\&D, debe ser incentivada en una sociedad, al igual que el desarrollo de las artes, ciencias, literatura, cultura y entretención, los que en su conjunto van conformando el acervo intelectual, científico y cultural de una nación. Pero solo la regulación equilibrada y eficiente de la propiedad intelectual determinará el desarrollo económico, tecnológico, social, educacional y cultural de las naciones.

Efectivamente pudiera pensarse que la solución es elevar al máximo la protección legal de los derechos de propiedad intelectual. Sin embargo, esto no es así, puesto que inevitablemente se terminaría por limitar cada vez más el dominio público; y no hay que olvidar que este no solo beneficia a la comunidad como un todo (uso pasivo), sino que constituye la base de la actividad inventiva y creativa de una sociedad (uso activo). Hoy en día, todo avance tecnológico, científico y cultural no es un hecho aislado, sino que debe mirarse dentro del contexto complejo propio de toda creación inserta en uno o más sectores del conocimiento de la humanidad. Ello se traduce en que toda obra intelectual creativa o científica es generada, aprovechando los esfuerzos colectivos desarrollados por muchos creadores o investigadores anteriores. Impedir o restringir el acceso libre y fluido a los conocimientos preexistentes a través de un exceso de propiedad intelectual, implica tener que pagar por ello, lo cual incrementará los costos de los futuros proyectos de I \& D.

Reconocemos absolutamente indispensable el cumplimiento y respeto de las leyes de propiedad intelectual, asociado a las medidas coercitivas respectivas. Pero igualmente debe quedar en claro, y esto muchas veces es olvidado en medio de la discusión acerca de la observancia de las leyes de propiedad intelectual, que utilizar adecuadamente las herramientas que fijan la extensión apropiada del dominio público (exclusiones, excepciones, limitaciones, plazos), reviste igual trascendencia como la adecuada protección de los derechos intelectuales, a la hora de asegurar incentivos a investigadores y creadores. Por consiguiente, el definir niveles de protección de los derechos intelectuales muy elevados o muy bajos, pone de igual forma en riesgo el desarrollo de innovaciones en el futuro. Es por ello que se hace indispensable fijar un cuidadoso equilibro de la función individual y social de la propiedad intelectual.

\section{BIBLIOGRAFÍA CITADA}

BOYLE, James (2003): "The second enclosure movement and the construction of the public domain?" Disponible en: <http://www.law.duke.edu/pd/papers/boyle.pdf> [fecha de consulta: 30 de septiembre de 2008] 
Cole, Julio H. (2003): "Propiedad Intelectual: Comentarios sobre algunas Tendencias recientes", Revista Empresa y Humanismo, Universidad de Navarra, vol. VI, N 1: pp. $35-48$.

CONSEJO NACIONAL de InNOVACIÓN PARA LA COMPETITIVIDAD (2006): “Informe final del Consejo Nacional de Innovación para la Competitividad, Asesor del Presidente de la República", Santiago. Disponible en: <http://www.consejodeinnovacion.cl/cnic/ servicios/documentos/web/download.php?id=54> [fecha de consulta: 30 de septiembre de 2008]

Cooter, Robert y Ulen, Thomas (1998): Derecho y Economía (México, Fondo de Cultura Económica) 686 pp.

Correa, Carlos M. (Director) (2005), "Propiedad Intelectual y Políticas de Desarrollo", en: Temas de Derecho Industrial y de la Competencia (Buenos Aires, Editorial Ciudad Argentina) Volumen 7, 489 pp.

FUNDACIÓN PARA LA DIFUSIÓN DEL CONOCIMIENTO Y EL DESARROLLO SUSTENTABLE VIA LIBRE (2007): Monopolios artificiales sobre bienes intangibles (Córdoba, Ediciones Fundación Vía Libre) 130 pp.

Gobierno De Chile (2006): Documento presentado al Comité Provisional sobre Propuestas relativas a un Programa de la OMPI para el Desarrollo (PCDA), Ginebra, 9 de enero de 2006. Disponible en: <www.direcon.cl/documentos/OMC/ propuesta_ompi.pdf> [fecha de consulta: 30 de octubre de 2008]

LESSIG, Lawrence (2004): Free Culture. How big media uses technology and the law to lock down culture and creativity (New York, The Pinguin Press) 345 pp.

Organisation fOr ECONOMic COOPERATION AND DEVElOPMENT (2008): OECD Science, Technology and Industry Outlook 2008 (París) 258 pp.

OrganizaCión Mundial De COMERCiO (2008) “¿Qué se entiende por "derechos de propiedad intelectual”?", Disponible en: <http://www.wto.org/spanish/tratop_s/ trips_s/intel1_s.htm> [fecha de consulta: 28 de octubre de 2008]

Schmitz VAccaro, Christian (2005): Propiedad Intelectual a la luz de los Tratados de Libre Comercio (Santiago, Editorial LexisNexis) 400 pp.

SCHMitz VACCARO, Christian (2006): "Propiedad Intelectual y Derecho de Autor, ¿Una división vigente?”, en: Morales Andrade, Marcos (edit.): “Temas Actuales de Propiedad Intelectual', (Santiago, Editorial LexisNexis) pp. 21-51.

Sherwood, Robert M. (1992): Propiedad Intelectual y Desarrollo Económico (Buenos Aires, Editorial Heliasta S.R.L.) 250 pp.

SUZUKI, Shin ichiro (2008): “Intellectual Property Protection and Economic Development", Apuntes/Diapositivas de Clase JPO/IPR Training Course for IP Trainers, Asia Pacific Industrial Property Center, Tokio, 12 de septiembre de 2008, 34 pp.

WORLDWIDE ACADEMY (2008): Propiedad Intelectual y Biotecnología (Ginebra, Organización Mundial de Propiedad Intelectual, Apuntes del curso) $452 \mathrm{pp}$.

ZuCCherino, Daniel R. (1995): El Derecho de Propiedad del Inventor (Buenos Aires, Ad-Hoc S.R.L.) 176 pp. 


\section{NORMAS CITADAS}

\section{Argentina:}

Ley No 22.362, de Marcas. Boletín Oficial, 2 de enero de 1981.

\section{Bolivia:}

Ley 1.322, de Derecho de Autor, 13 de abril de 1992

Chile:

Ley No 17.336, de Propiedad Intelectual. Diario Oficial, 2 de octubre de 1970 (modificada en diversas oportunidades).

D.F.L. No 3 que fija el Texto refundido, coordinado y sistematizado de la Ley No 19.039, de Propiedad Industrial. Diario Oficial, 20 de junio de 2006.

\section{Internacional:}

Acuerdo sobre los Aspectos de los Derechos de Propiedad Intelectual relacionados con el Comercio (ADPIC), 15 de abril de 1994.

Convenio de París para la Protección de la Propiedad Industrial, 20 de marzo de 1883.

"Declaración de Ginebra sobre el futuro de la OMPI", Asamblea General de la Organización Mundial de la Propiedad Intelectual (OMPI), 4 de octubre de 2004. Disponible en: <http://www.cptech.org/ip/wipo/genevadeclaration.html> [fecha de consulta: 28 de octubre de 2008]

Tratado de la OMPI sobre Derecho de Autor (WCT), 20 de diciembre de 1996.

Tratado de la OMPI sobre Interpretación o Ejecución y Fonogramas (WPPT), 20 de diciembre de 1996.

Tratado de Libre Comercio entre Chile y Estados Unidos de América, 6 de junio de 2003. 
